\title{
AGE SPECIFIC RELATION IN BLOOD PRESSURE WITH SOME ANTHROPOMETRICAL VARIABLES OF WOMEN IN LATVIA: A RURAL - URBAN COMPARISON
}

\author{
Dzintra Kažoka, JĀNIS VĒTra \\ Institute of Anatomy and Anthropology, Riga Stradiņš University, Latvia
}

\begin{abstract}
The aims of this study were to describe and compare the relationships between some variables of anthropometrical measurements and the blood pressure of women according to the age group categories in the urban and the rural population in Latvia. For this purpose 369 women (urban, 197 and rural, 172) were anthropometrically examined during the period of 2001-2005. The body height, the body weight, three circumferences (chest, waist, hip) and four skinfolds (biceps, triceps, subscapular, suprailiac) were measured. The body mass index (BMI) was calculated and studied. The difference between rural and urban women in systolic, diastolic and mean arterial blood pressure was found to be statistically significant. All the variables of the anthropometrical measurements and the age were significantly positive with blood pressure. The relationships between the variables of anthropometrical measurements and the age were assessed through the stepwise multiple regression analysis. All the anthropometrical variables appear as significant predictors of blood pressure and enter the regression equations in urban and rural populations of women in Latvia. Future studies, based on the interpretation of anthropometric measurements and their changes in the urban and rural women aged 21-45 years in Latvia, should also be carried out.
\end{abstract}

Keywords: blood pressure, anthropometry, urban and rural women, age 


\section{INTRODUCTION}

Urban and rural differences in anthropometrical parameters have come into the focus of interest in the last years. There are several studies which have reported differences in the samples from various countries, cultures and various age ranges $[5,11]$. In different age women are characterized by a different body shape and the body composition, and there are important differences between the child, the adolescent and the adult age. Regardless of human age, the measurement of the blood pressure should be a part of the routine physical examination. Blood pressure (BP) is an important physiological marker, and it has a great etiological significance in the epidemiology of different problems [9]. Elevated blood pressure is a well recognized risk factor for cardiovascular diseases, like the coronary artery disease, the stroke and heart failure. Detecting high blood pressure at young ages is an important action for the control and the prevention of hypertension in older age groups. Its value as a screening tool for hypertension in adults has long been documented $[1,8]$.

Some authors report that different anthropometric measurements such as the body height, the body weight, the BMI, the waist and the hip circumferences, the thicknesses of different skinfolds are used at present as risk factors for cardiovascular diseases $[2,10]$.

Therefore, the aims of this study were to describe and compare the relationships between some variables of anthropometrical measurements and the blood pressure of women according to the age group categories in urban and the rural population in Latvia.

\section{MATERIAL AND METHODS}

This population study of women was carried out in Latvia (2001-2005). A total 369 adult females (urban, 197 and rural, 172) aged 21-45 were measured for the body height, the body weight, three circumferences (chest, waist, hip), four skinfold thicknesses (biceps, triceps, subscapular, suprailiac) and the blood pressure. All the anthropometrical measurements were made according to the Martin's and Saller's method [12, 13]. The body height was measured using a standard the "Siber-Hegner \& Co" anthropometer. For the evaluation of the body weight, we used a portable scale with a $0.1 \mathrm{~kg}$ precision. Participants were weighed wearing light clothing and no shoes. 
The body mass index (BMI) was computed using the following standard equation: $\mathrm{BMI}\left(\mathrm{kg} / \mathrm{m}^{2}\right)=$ weight $(\mathrm{kg}) /$ height $\left(\mathrm{m}^{2}\right)$ [3]. The women were classified as underweight $(\leq 18.49)$, normal weight (18.5-24.99), overweight $(25.0-29.99)$ and obese $(\geq 30.0)$ according to the classification system recomended by the World Health Organization [20].

Skinfolds measurements were performed using the caliper with $0.2 \mathrm{~mm}$ precision. The circumferences of the chest, the waist and the hip were measured with a flexible tape to the nearest $0.1 \mathrm{~cm}$.

All the women were classified by their present age into three groups (21-25, 26-35, 36-45).

Blood pressure was measured on the right arm and at the level of the heart after relaxing for 5 minutes while sitting in the vertical position, using the digital and validated blood pressure device ("Omron", RX-M). The physiometric variables included the measurement of the systolic blood pressure (SBP) and the diastolic blood pressure (DBP). The mean arterial blood pressure (MBP) was calculated for each of the two readings taken for SBP and DBP by using the formula [17]: $\mathrm{MBP}=\mathrm{DBP}+(\mathrm{SBP}-\mathrm{DBP}) / 3$.

The collected data were analyzed by IBM SPSS Statistics (version 20.0). Means, standard deviations, independent samples t-test, the Pearson's correlation test, the stepwise multiple regression analysis were used to investigate the relationships between the anthropometrical measurements and blood pressure among urban and rural women in different age.

\section{RESULTS}

The data of the age related variables of the anthropometrical measurements of the urban and the rural women are presented in Table 1 . It is evident that the largest part of the mean values of these traits increase after the age of 25 in both the rural and the urban areas.

The body heights for the urban women show a considerably higher mean value than the rural women at the age 21-25 years, whereas, for the rural women a reverse trend is noticed from the age of 26 to 35 years. At the age of $36-45$ years rural women show a slightly higher value of height than their urban women. 
Table 1. Age related variables of anthropometrical measurements among women in urban and rural areas in Latvia $(m \pm S D)$.

\begin{tabular}{|c|c|c|c|c|c|c|c|}
\hline & & \multicolumn{6}{|c|}{ Age groups (years) } \\
\hline & & \multicolumn{2}{|c|}{$21-25$} & \multicolumn{2}{|c|}{$26-35$} & \multicolumn{2}{|c|}{$36-45$} \\
\hline & & $\begin{array}{c}\text { urban } \\
(n=111)\end{array}$ & $\begin{array}{c}\text { rural } \\
(\mathrm{n}=79)\end{array}$ & $\begin{array}{l}\text { urban } \\
(\mathrm{n}=42)\end{array}$ & $\begin{array}{c}\text { rural } \\
(n=48)\end{array}$ & $\begin{array}{l}\text { urban } \\
(n=44)\end{array}$ & $\begin{array}{c}\text { rural } \\
(n=45)\end{array}$ \\
\hline \multicolumn{2}{|c|}{ body height $(\mathrm{cm})$} & $165.5 \pm 6.0$ & $165.4 \pm 6.4$ & $164.6 \pm 6.6$ & $165.9 \pm 6.1$ & $164.2 \pm 8.1$ & $164.3 \pm 5.2$ \\
\hline \multicolumn{2}{|c|}{ body weight $(\mathrm{kg})$} & $57.6 \pm 7.9$ & $61.9 \pm 10.4$ & $62.0 \pm 11.7$ & $66.9 \pm 12.9$ & $68.6 \pm 13.3$ & $73.7 \pm 14.9$ \\
\hline \multicolumn{2}{|c|}{ BMI $\left(\mathrm{kg} / \mathrm{m}^{2}\right)$} & $21.06 \pm 2.6$ & $22.6 \pm 3.7$ & $22.8 \pm 3.7$ & $24.4 \pm 4.8$ & $25.6 \pm 5.6$ & $27.2 \pm 5.2$ \\
\hline \multirow{3}{*}{$\begin{array}{l}\text { circum- } \\
\text { ferences } \\
\quad(\mathrm{cm})\end{array}$} & chest & $82.4 \pm 5.0$ & $85.4 \pm 6.4$ & $84.8 \pm 7.8$ & $88.2 \pm 8.9$ & $89.7 \pm 10.5$ & $93.0 \pm 8.8$ \\
\hline & waist & $66.2 \pm 6.5$ & $69.5 \pm 7.9$ & $71.4 \pm 8.6$ & $74.8 \pm 10.7$ & $77.5 \pm 12.1$ & $82.3 \pm 12.6$ \\
\hline & hip & $92.1 \pm 6.8$ & $95.2 \pm 7.5$ & $97.8 \pm 9.5$ & $98.6 \pm 10.4$ & $99.8 \pm 10.7$ & $104.8 \pm 10.9$ \\
\hline \multirow{4}{*}{$\begin{array}{l}\text { skin- } \\
\text { folds } \\
(\mathrm{mm})\end{array}$} & biceps & $6.7 \pm 2.2$ & $7.3 \pm 2.8$ & $7.1 \pm 2.9$ & $7.2 \pm 3.4$ & $8.2 \pm 3.2$ & $9.2 \pm 4.0$ \\
\hline & triceps & $11.5 \pm 3.0$ & $12.8 \pm 3.8$ & $12.7 \pm 4.0$ & $13.4 \pm 4.5$ & $14.4 \pm 4.3$ & $15.8 \pm 5.7$ \\
\hline & $\begin{array}{l}\text { subsca- } \\
\text { pular }\end{array}$ & $11.9 \pm 3.7$ & $13.3 \pm 4.8$ & $14.0 \pm 4.9$ & $16.0 \pm 7.2$ & $16.4 \pm 6.9$ & $19.4 \pm 7.5$ \\
\hline & $\begin{array}{l}\text { suprai- } \\
\text { liac }\end{array}$ & $12.7 \pm 4.5$ & $13.8 \pm 4.9$ & $14.2 \pm 5.0$ & $15.1 \pm 5.9$ & $17.0 \pm 7.2$ & $18.7 \pm 7.9$ \\
\hline
\end{tabular}

$\mathrm{n}$ - number of women; $\mathrm{m}$ - mean; SD - standard deviation; BMI - body mass index

When the data on the body height are analyzed, a rise is seen after the age of 25 years among the rural as well as the the urban women. Similar trends were observed for the BMI, the chest, the waist, the hip circumferences and four skinfold thicknesses in three age groups. Rural women show considerably higher values than urban women. The differences between the means of urban and rural areas were found to be statistically significant $(\mathrm{p}<0.001)$.

The changes of means for the age related systolic and diastolic blood pressures in rural and urban areas are presented in Table 2. At the age of 21-25 years the mean values of SBP, DBP and MBP also show consistently higher values in the urban women than the rural women. Later an upward trend of the mean values of SBP, DBP and MBP with the age is found for the women in urban and rural areas. In rural areas women have a relatively higher rate of increase in the levels of systolic and diastolic blood pressure with advancing age as compared with the women in the urban areas.

The correlation coefficients of systolic and diastolic blood pressure in relation to the age and some variables of anthropometrical measurements among adult women in urban and rural areas are shown in Table 3. The age, the body weight, the BMI, the chest, the waist, the hip circumferences and four skinfold 
thicknesses significantly $(\mathrm{p}<0.01)$ correlated with the systolic and the diastolic blood pressure for women in both rural and urban areas.

Table 2. Age related variables of blood pressures among women in urban and rural areas in Latvia $(m \pm S D)$.

\begin{tabular}{|c|c|c|c|c|c|c|}
\hline & \multicolumn{6}{|c|}{ Age groups (years) } \\
\hline & \multicolumn{2}{|c|}{$21-25$} & \multicolumn{2}{|c|}{$26-35$} & \multicolumn{2}{|c|}{$36-45$} \\
\hline & $\begin{array}{c}\text { urban } \\
(n=111)\end{array}$ & $\begin{array}{c}\text { rural } \\
(n=79)\end{array}$ & $\begin{array}{l}\text { urban } \\
(\mathrm{n}=42)\end{array}$ & $\begin{array}{c}\text { rural } \\
(n=48)\end{array}$ & $\begin{array}{l}\text { urban } \\
(n=44)\end{array}$ & $\begin{array}{c}\text { rural } \\
(n=45)\end{array}$ \\
\hline SBP $(\mathrm{mm} / \mathrm{Hg})$ & $119.6 \pm 12.1$ & $118.6 \pm 10.4$ & $124.1 \pm 11.0$ & $125.4 \pm 14.0$ & $130.0 \pm 18.9$ & $134.3 \pm 15.4$ \\
\hline $\mathrm{DBP}(\mathrm{mm} / \mathrm{Hg})$ & $82.8 \pm 8.7$ & $80.9 \pm 8.8$ & $82.6 \pm 9.0$ & $83.8 \pm 10.2$ & $89.1 \pm 13.5$ & $89.5 \pm 11.4$ \\
\hline $\mathrm{MBP}(\mathrm{mm} / \mathrm{Hg})$ & $95.1 \pm 8.9$ & $93.4 \pm 8.2$ & $96.5 \pm 8.9$ & $97.7 \pm 10.5$ & $102.7 \pm 14.5$ & $104.4 \pm 12.0$ \\
\hline
\end{tabular}

$\mathrm{n}$ - number of women; $\mathrm{m}$ - mean; SD - standard deviation; SBP - systolic blood pressure; $\mathrm{DBP}$ - diastolic blood pressure; MBP - mean arterial blood pressure

Table 3. The correlation coefficients of the systolic and the diastolic blood pressure in relation to the age and some variables of anthropometrical measurements among adult women in urban and rural areas in Latvia.

\begin{tabular}{ccc|cc|cc|cc}
\hline & \multicolumn{4}{c}{ SBP } & \multicolumn{4}{c}{ DBP } \\
\cline { 2 - 10 } Variables & \multicolumn{2}{c}{ urban } & \multicolumn{2}{c}{ rural } & \multicolumn{2}{c}{ urban } & \multicolumn{2}{c}{ rural } \\
\cline { 2 - 10 } & $\mathbf{r}$ & $\mathbf{p}$ & $\mathbf{r}$ & $\mathbf{p}$ & $\mathbf{r}$ & $\mathbf{p}$ & $\mathbf{r}$ & $\mathbf{p}$ \\
\hline DBP & 0.714 & $\mathrm{p}<0.01$ & 0.731 & $\mathrm{p}<0.01$ & - & - & - & - \\
\hline MBP & 0.901 & $\mathrm{p}<0.01$ & 0.906 & $\mathrm{p}<0.01$ & 0.947 & $\mathrm{p}<0.01$ & 0.951 & $\mathrm{p}<0.01$ \\
\hline age & 0.450 & $\mathrm{p}<0.01$ & 0.544 & $\mathrm{p}<0.01$ & 0.274 & $\mathrm{p}<0.01$ & 0.353 & $\mathrm{p}<0.01$ \\
\hline body weight & 0.410 & $\mathrm{p}<0.01$ & 0.377 & $\mathrm{p}<0.01$ & 0.323 & $\mathrm{p}<0.01$ & 0.291 & $\mathrm{p}<0.01$ \\
\hline BMI & 0.481 & $\mathrm{p}<0.01$ & 0.434 & $\mathrm{p}<0.01$ & 0.374 & $\mathrm{p}<0.01$ & 0.312 & $\mathrm{p}<0.01$ \\
\hline chest circumference & 0.419 & $\mathrm{p}<0.01$ & 0.420 & $\mathrm{p}<0.01$ & 0.331 & $\mathrm{p}<0.01$ & 0.302 & $\mathrm{p}<0.01$ \\
\hline waist circumference & 0.490 & $\mathrm{p}<0.01$ & 0.530 & $\mathrm{p}<0.01$ & 0.344 & $\mathrm{p}<0.01$ & 0.380 & $\mathrm{p}<0.01$ \\
\hline hip circumference & 0.434 & $\mathrm{p}<0.01$ & 0.472 & $\mathrm{p}<0.01$ & 0.331 & $\mathrm{p}<0.01$ & 0.377 & $\mathrm{p}<0.01$ \\
\hline biceps skinfold & 0.309 & $\mathrm{p}<0.01$ & 0.263 & $\mathrm{p}<0.01$ & 0.253 & $\mathrm{p}<0.01$ & 0.206 & $\mathrm{p}<0.01$ \\
\hline triceps skinfold & 0.181 & $\mathrm{p}<0.01$ & 0.301 & $\mathrm{p}<0.01$ & 0.136 & $\mathrm{p}<0.01$ & 0.180 & $\mathrm{p}<0.01$ \\
\hline subscapular skinfold & 0.408 & $\mathrm{p}<0.01$ & 0.359 & $\mathrm{p}<0.01$ & 0.307 & $\mathrm{p}<0.01$ & 0.274 & $\mathrm{p}<0.01$ \\
\hline suprailiac skinfold & 0.318 & $\mathrm{p}<0.01$ & 0.270 & $\mathrm{p}<0.01$ & 0.249 & $\mathrm{p}<0.01$ & 0.160 & $\mathrm{p}<0.01$ \\
\hline
\end{tabular}

SBP - systolic blood pressure; DBP - diastolic blood pressure; MBP - mean arterial blood pressure; $\mathrm{BMI}$ - body mass index

There are statistically significant associations $(\mathrm{p}<0.05)$ between the systolic blood pressure and the body height for the urban women $(\mathrm{r}=-0.138)$ and for the rural women $(r=-0.142)$. 
To evaluate the effects of the anthropometric variables on blood pressure simultaneously, a stepwise multiple regression was carried out with the age adjusted systolic and diastolic blood pressure as dependent variables and the age adjusted anthropometric variables as independent variables (Table 4).

Table 4. Distribution of thecoefficient of determinations $\left(R^{2}\right)$ and the variance ratio $(F)$ for SBP and DBP for the body weight model with the other variables among women in urban and rural areas in Latvia.

\begin{tabular}{ccc|cc|cc|ccc}
\hline $\begin{array}{c}\text { Blood pressure model } \\
\text { with the other variabes } \\
\text { (assumed body weight }\end{array}$ & \multicolumn{4}{c}{$\mathbf{S B P}^{*}$} & \multicolumn{2}{c}{ DBP $^{*}$} & \multicolumn{2}{c|}{ SBP* $^{*}$} & \multicolumn{2}{c}{ DBP $^{*}$} \\
\cline { 2 - 10 } as a constant predictor) & urban & rural & urban & rural & urban & rural & urban & rural \\
\hline $\begin{array}{c}\text { body weight, } \\
\text { body height }\end{array}$ & 0.163 & 0.145 & 0.100 & 0.085 & 86.13 & 52.57 & 49.39 & 28.86 \\
\hline $\begin{array}{c}\text { body weight, } \\
\text { BMl }\end{array}$ & 0.208 & 0.158 & 0.156 & 0.105 & 116.36 & 58.35 & 82.08 & 36.39 \\
\hline $\begin{array}{c}\text { body weight, } \\
\text { biceps skinfold }\end{array}$ & 0.223 & 0.166 & 0.173 & 0.116 & 126.97 & 61.86 & 92.93 & 40.76 \\
\hline $\begin{array}{c}\text { body weight, } \\
\text { triceps skinfold }\end{array}$ & 0.222 & 0.157 & 0.165 & 0.101 & 126.24 & 57.80 & 87.60 & 34.90 \\
\hline $\begin{array}{c}\text { body weight, } \\
\text { subscapular skinfold }\end{array}$ & 0.218 & 0.169 & 0.180 & 0.110 & 123.33 & 63.06 & 97.51 & 38.28 \\
\hline $\begin{array}{c}\text { body weight, } \\
\text { suprailiac skinfold }\end{array}$ & 0.198 & 0.160 & 0.157 & 0.111 & 108.87 & 59.28 & 82.23 & 38.93 \\
\hline
\end{tabular}

${ }^{*} \mathrm{p}<0.001, \mathrm{SBP}$ - systolic blood pressure; DBP - diastolic blood pressure; BMI - body mass index

It is assumed that the body weight acts as a constant significant predictor of the systolic and the diastolic blood pressure. All the "F" ratios for urban and rural

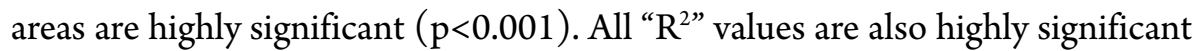
$(p<0.001)$ for both areas. Therefore, it is difficult to assess the difference of the effects of these anthropometric variables on their blood pressures in urban or rural area among women in Latvia.

\section{DISCUSSION}

The worldwide variation in the body size, the proportions and physique exists between the genders and among different populations [18, 19]. Many studies demonstrate that anthropometric values may vary between rural and urban residents $[7,14]$. The difference between the modern lifestyle in urban areas 
and the traditional way of life in rural areas may affect the population's health in developing countries. Studying this variation in the body size and physique has long been the interest of anthropologists as it helps in understanding the health, the nutritional status and the degree of environmental adaptation of a population. Environmental and cultural factors are responsible for urban and rural differences. These differences may be due to the demographic and epidemiologic transition, as these countries become more resourceful economically (socioeconomic transition). The urbanization process, however, occurs under different circumstances among countries [6]. When some comparisons of urban and rural populations are made, conditions in urban areas are habitually reported as superior to those in rural areas.

In this study, the rise in blood pressure with age is moderate among urban and rural women in Latvia. There was a general tendency of the systolic and the diastolic levels of blood pressure to increase with advancing age in both the urban and the rural populations. The differences of the systolic, the diastolic and the mean arterial blood pressure in the urban and rural areas have been found to be statistically significant $(\mathrm{p}<0.01)$. A consistent increasing trend of systolic, diastolic and mean arterial blood pressure has been found in urban females. This suggests that different environmental factors have a positive effect to the increase of the blood pressure. The present study is consistent with the findings reported by several studies $[16,21]$.

In the present study we underline that there is a trend of increase in the body weight, the body mass index and skinfold thicknesses with the advancement of the age among urban and rural women in Latvia.

But, the mean variables of the body height show a reverse pattern - a decrease in the body height is observed from the youngest age group to the oldest age group in urban women. A similar trend of decrease in the body height is observed by other authors $[6,18]$.

Urban women are taller only at the age of 21-25 years, but rural women are taller in all the oldest age groups (26-35 years and $36-45$ years). In all the age groups rural women have broader shoulders and hips than the urban women. The differences of other variables like the body weight, the BMI and three skinfold thicknesses were statistically significant $(p<0.001)$ for all the age groups.

A highly significant positive effect $(p<0.01)$ of the age and the variables of the anthropometrical measurements have been found on the systolic and the 
diastolic pressure in rural and urban women. All the women showed variability in the blood pressure especially in the age groups after 25 years.

This phenomenon is related to several factors and conditions that may play a role in its development $[4,21]$. Some authors observe that women after the age of 35 years and older have a tenfold increased risk for hypertension as compared to younger women, and the differences between the modern and traditional way of living in the urban and the rural areas have a great impact on the health condition [15].

In this study we suggest that the age associated changes with all the studied anthropometrical variables are inevitable for women. These changes are associated with some specific changes (physiological, hormonal, etc.) in women.

In this study all the anthropometrical variables were used to predict blood pressure in a stepwise multiple regression analysis in urban and rural women separately. All the anthropometrical variables appear as significant predictors of blood pressure and enter the regression equations in both populations.

\section{ACKNOWLEDGEMENTS}

This study was undertaken as a part of the investigation "Appreciation of biological status of women in Latvia”. It was funded by the European Union Structural Funds for Scientific Research. In addition, acknowledgements are given to the following institutions: Riga Stradiňš University, the Institute of Anatomy and Anthropology, the Department of Anthropology and Physics Department. The authors wish to thank the medical nurses of the anthropology unit for helping them during anthropometric measurements of women.

\section{REFERENCES}

1. Adedoyin R. A., Mbada C. E., Bisiriyu L. A., Adebayo R. A., Balogun M. O., Akintomide A. O. (2009). Relationship of anthropometric indicators with blood pressure levels and the risk of hypertension in Nigerian adults. Int J Gen Med, 1, 33-40.

2. Amirkhizi F., Siasi F., Minaei S., Jalali M., Dorosti M. A., Chamari M. T. (2009). Assessment of blood pressure status and its relationship with anthropometric indices among women in rural areas of Kerman province, Iran. Yafteh, 10, 2, 31-38.

3. Badaruddoza A., Brar S.K., Kumar R. (2009). Age specific relation of blood pressure with anthropometric variables among 19-24 years Punjabi female youth of Amritsar city in Punjab, India. Anthropologist, 11, 207-211. 
4. Badaruddoza A., Gill K., Sandhu P. K. (2011). Factor analysis of anthropometric, physiometric and metabolic risk traits associated with cardiovascular diseases in North Indian Punjabi adults. J. Applied Sci, 11, 2843-2848.

5. Baumgartner R. (1997). Body composition and anthropometry. In: Garry P. J., Owen G. M., Eldridge T. O. (Eds), The New Mexico Aging Process Study from the Clinical Nutrition Program. University of New Mexico, 88-145.

6. Eveleth P. B., Tanner J. M. (1990). World-wide variation in human growth. $2^{\text {nd }}$ edn. Cambridge: Cambridge University Press.

7. Fezeu L., Kengne A. P., Balkau B., Awah P. K., Mbanya J. C. (2010). Ten-year change in blood pressure levels and prevalence of hypertension in urban and rural Cameroon. J Epidemiol Community Health, Apr, 64, 4, 360-365.

8. Gelber R. P., Gaziano J. M., Orav E. J., Manson J. E., Buring J. E., Kurth T. (2008). Measures of obesity and cardiovascular risk among men and women. J Am Coll Cardiol, 52, 605-615.

9. Gerber L. M., Halberstein R. A. (1999). Blood pressure: Genetic and Environmental Influences. Hum Biol, 71, 4, 467-473.

10. Gupta R., Rastogi P., Sarna M., Gupta V. P., Sharma S. K., Kothari K. (2007). Body-mass index, waist-size, waist-hip ratio and cardiovascular risk factors in urban subejcts. J. Assoc. Phys. India, 55, 621-627.

11. Haveman-Nies A., de Groot L. C., van Staveren W. A. (2003). Dietary quality, lifestyle factors and healthy aging in Europe: the SENECA study. Age and Ageing, 32, 427-434.

12. Martin R. Lehrbuch der Anthropologie. I und II Bd. Jena, 1928.

13. Martin R., Saller K. Lehrbuch der Anthropologie. Stuttgart: Fischer, Bd. I., 1957.

14. Minh H. V., Huong D. L., Giang K. B. (2008). Self-reported chronic diseases and associated sociodemographic status and lifestyle risk factors among rural Vietnamese adults. Scand J Public Health, 36, 629-634.

15. Mirmiran P., Esmaillzadeh A., Azizi F. (2004). Detection of cardiovascular risk factors by anthropometric measures in Tehranian adults: receiver operating characteristic (ROC) curve analysis. Eur J Clin Nutr, 58, 1110-1118.

16. Obidike E. O. (2007). Anthropometry and blood pressure in Nigerian children. Orient Journal of Medicine, 19, 1-4, 49-53.

17. Perusse L., Rice T., Bouchard C., Vogler G. P., Rao D. C. (1989). Cardiovascular risk factors in a French-Canadian population: resolution of genetic and familial environment effects on blood pressure by using extensive information on environment correlates. Am J Hum Genet, 45, 240-252.

18. Perissinoto E., Pisent C., Sergi G., Grigoletto F., Enzi G. (2002). Anthropometric measurements in the elderly: age and gender differences. British Journal of Nutrition, 87, 177-186.

19. Siniarska A., Wolanski N. (2000). Ecology of Aging. Delhi, 216 p. 
20. WHO Expert Committee (1995) The Use and Interpretation of Anthropometry. WHO Technical Report Series no. 854. Geneva: WHO.

21. Yalcin B. M., Sahin E. M., Yalcin E. (2005). Which anthropometric measurement is most closely related to elevated blood pressure? Family Practice, 22, 541-547.

\section{Address for correspondence:}

Dzintra Kažoka

Institute of Anatomy and Anthropology

Riga Stradiņš University

Kronvalda blv. 9, Riga, Latvia, LV-1010

E-mail: Dzintra.Kazoka@rsu.lv 